\title{
Discovering Myself, a Journey of Rediscovery
}

\author{
Waldo Roeg
}

\subsection{Introduction}

I currently work as a Peer Recovery Trainer at Central North West London NHS Foundation Trust (CNWL) Recovery College. I am also a consultant for Implementing Recovery through Organizational Change (ImROC). But my life was not always so. Indeed, I have used services now for over 35 years, both for my drug and substance misuse and for my mental health. In this chapter, I tell the story of my recovery: of the many wonderful people who supported me in my journey; and of how my experience is now helping me in my current role working with others towards their own recovery.

\subsection{Homeless and Without Hope}

It all started when I was a teenager. I came from an affluent family, had a good career in films for 25 years ... and learned how to hide my problems. Well that couldn't last. It ended 17 years ago now when I had a major breakdown and lost everything. I became bankrupt, so lost my home. I lost my career as I had been 'found out'. I lost my partner, family, dignity and status in society. But most of all I lost myself.

I ended up living on the street with only the clothes I stood up in. I moved from one dealer to another, doing odd jobs for them for measly bits of drugs and the crumbs from their tables, turning to petty crime to fund my meager existence. I

\footnotetext{
W. Roeg $(\bowtie)$

Central and North-West London Recovery and Wellbeing College, Central and North West

NHS Foundation Trust, London, UK
} 
ended up in constant conflict with law enforcement and in and out of police cells. My only goal was to survive. My existence was so precarious that I feared that trying to improve my situation-risk what little I had-might rebound badly on me. I learned that any efforts that I made did little to improve my situation. I felt I had become worthless and became very cautious about making any efforts to move on.

\subsection{Point Zero}

All the stigma associated with my mental health and substance misuse was heightened $100 \%$ by being in such poverty and so reliant on state aid as my only income ... and a very small income it was because I was of 'no fixed abode'. I was made to feel utterly useless by services who saw me only as another worthless mad junkie on the streets. They tried to mitigate my symptoms with medication and it made me believe that was all there was going to be for me. My interaction with services at the time was minimal-just enough to ensure a supply of medication.

I did just enough to survive and became acclimatized to it. My own sense of shame and stigma was such that I adopted the way of the street just to be able to identify with something. I worked out that it was easier to stop short of doing anything to better myself as I thought it would not yield sufficient gain to outweigh the extra effort. This gave people the impression I was lazy. I lost any thought of being accepted in wider society. My expectations of myself were zero and the expectations of everyone around me were zero.

I was so lost I felt as though all the possibilities of life were far beyond my reach. I told myself that, at 42, I had 'semi retired'. I had been going in and out of hospital and after my last admission I finally surrendered: gave myself up entirely to services agreeing to anything they demanded of me. They agreed to put me into a hostel.

\subsection{Housing First}

This was the first stable roof I had for 2 years. It also meant I could claim state benefits and have a small but steady income. They started the process of rehousing me. I was very lucky because I met another resident while I was at the hostel. She was the first person in years who didn't view me as just a 'mad junkie on the streets'. She was utterly non-judgmental and actually seemed to be impressed by me. We had a baby whilst we were in the hostel. After 2 years in the hostel we went into temporary housing for another 2 years: it was a place of our own and it made a huge difference.

This stability allowed me to get on top of my drug taking but not my mental health. I was still struggling daily and isolating myself indoors. The constant struggle to survive sapped all hope. There were times when the constant worry about 
benefits, finding the rent, the possibility of losing our flat and whether or not there would be enough for us to eat, was almost as bad for my mental health as being on the street. It was having a baby to look after that gave me something to live for.

\subsection{Opportunity}

We were finally rehoused permanently in 2005. I continued to use services but it felt I was on a treadmill going nowhere. Expectations around what I could do were very low. I had left school with no qualifications and had only worked in the 'arts' so felt I had been left on the shelf of possibilities. Eventually I was asked if I wanted to do a work placement. The low expectations I had of myself meant that I only agreed to do this if they guaranteed it would not lead to me having to take work. The thought of what working might do to my state benefits-the risk that I might be worse off financially by working-terrified me. They agreed to my conditions and I went to a work placement in Community Day Services supporting a gardening group in the afternoons.

\subsection{Control}

I was given a set of keys to the building as soon as I arrived. This was the first time in a very long time that I felt trusted-especially with a building full of computers. It was the first time I felt I was being valued and treated with dignity and respect. What is more, other staff listened to me when I spoke up. I was really made to feel a part of the team. This very different relationship cost very little but had huge implications for me.

\subsection{Hope}

It was not long before I moved on to volunteering for 3 days a week at the Day Centre and really working as a Peer Support Worker. I was using my own experiences to model a sense of hope that recovery could be a possibility for people using the Centre. Being able to do this really fired my enthusiasm and passion and I soon found myself with a determined goal. I had been on the receiving end of help for so long that I had forgotten just how powerful being in a position to help others could be, even if this was just making someone a cup of tea.

The volunteer work gave me access to training and I started accessing the mental health training for staff within the local authority where I now work (CNWL, Camden and North West London). I also had my first experience with 'Wellness Recovery Action Plans'(WRAP, [1]). I found there were so many strategies I had been using to survive without realizing it. Having a plan and being 
conscious of my aspirations allowed me to start to thrive rather than just survive. I began to learn how to manage my own difficulties and get the best out of my situation.

\subsection{Recovery}

Getting involved with WRAP led to my first real experience in coproduction. A group of staff members and people who used the service collaborated to create our own 'Health and Wellbeing Plans'. These are now used across CNWL have led to all sorts of opportunities for me.

Finally, in peer support I had found something I wanted to do and felt I was good at. I was able to access the first Peer Support Training programme at CNWL. This was the first time I had ever undertaken any sort of academic training and I completed it! I was asked to be a part of CNWL's bid to become part of the initial Implementing Recovery through Organisational Change programme (ImROC, [2]). As part of ImROC, CNWL started to develop Peer Support Worker positions in services; set up a Recovery College and looked at recovery education; and developed a more recovery-focused approach to risk. Involvement with these endeavors at a Trust level led to me becoming a consultant with the ImROC team providing support to other organisations across the UK in their quest to develop more recoveryfocused services.

Finally I took the plunge and went back to work as a Peer Recovery Trainer when CNWL opened our Recovery and Wellbeing College in 2012. This is not a sheltered position. I was recruited like any other member of staff, however I was supported in finding the right amount of hours so that I was assured of being better off financially in work.

This opened a new horizon for me with a host of new opportunities. It has given me a new sense of hope and, although I don't earn a great deal, it is enough to help enable me to thrive. I am now a contributing citizen putting the skills I have to good use. I am building on what is strong in me, rather than what is wrong with me. I still take medication, and find some things a real struggle, but now I am someone who both uses services and helps to deliver services. In both of these roles I have witnessed many changes both in services and in myself.

\subsection{What I Have Learned}

I was once asked to write a list of the things that have helped in my own recovery journey. The list is quite long! But I would not wish to shorten it. Each in different ways has contributed. Together they make an unbeatable combination:

1. Acceptance.

2. Feeling a part of the community both at home and at work: the feeling that you belong. 
3. A feeling of independence.

4. A self-management plan.

5. Being confident to advocate for myself.

6. Being valued for what I can contribute: moving from feeling grateful to people to discovering I have qualities that are valued.

7. Stable housing.

8. Being an active citizen and feeling my social status is not less than the people who support me.

9. Overcoming my own stigma and shame.

10. Gaining a sense of momentum.

11. Having a small group of people that looked at me differently that helped me to look at myself differently.

12. Changing attitudes.

13. Use of a different language — the language of recovery.

Most of these things cost nothing extra. For the most part, they are about a different sort of interaction and different relationships. The Recovery College where I work, and others like it, embody so many of the things that have helped me in my journey of recovery. 'Patients' become 'students' and relationships are transformed through coproduction. They challenge stigma and genuinely recognize the strengths and contribution that everyone can make.

\subsection{Conclusions}

In this chapter, I have told the story of my own experience of recovery from mental health problems complicated by drug misuse. I have also offered a brief reflection on how I am now building on what I learned from that experience in my current work supporting others in their recovery.

Recovery is a contested term [3]. We use it in the recovery movement to mean recovering a good quality of life as defined by what is important to the person concerned (i.e. that person's individual values). So defined, the factors that contribute to an individual's recovery journey are necessarily very diverse. There are correspondingly many theories of recovery [4]. I indicated in the last section above the long list of factors that contributed to my own recovery. But if I had to choose just three factors that in my experience and the experience of others, seem essential, they would be the three by which the very culture of the recovery college movement is defined, hope, control and opportunity.

Acknowledgements In my current roles, both as a peer trainer in recovery and as a consultant for ImROC (see introduction), I have had the opportunity to work alongside some of the best people I have ever worked with. Sharing their passion has been a huge part of what has inspired me in my own recovery over the last few years.

My story as told in this chapter was published originally in the journal Mental Health and Social Inclusion [5]. I am very grateful to Mental Health and Social Inclusion and to its editor, Rachel Perkins, for permission to reproduce it here. 


\subsection{Guide to Further Sources}

For further information on the recovery movement please see:

Meddings, S., McGregor, J., Roeg, W. and Shepherd, G. (2015), "Recovery colleges: quality and outcomes", Mental Health and Social Inclusion, Vol. 19 No. 4, pp. 212-221. https://doi.org/10.1108/MHSI-08-2015-0035

Slade, M., Oades, L., and Jarden A., (eds) (2017) Wellbeing, Recovery and Mental Health (2017) (eds). Cambridge: Publisher Cambridge University Press. ISBN1107543053, 9781107543058

And a recently released film on recovery by the author at: https://www.youtube. com/watch?v=9iO4D0j_0A8

\section{References}

1. Copeland ME. Wellness Recovery Action Plan (WRAP). 1997. www.mentalhealthrecovery.com.

2. http://www.imroc.org/about-us/.

3. Slade M, Amering M, Farkas M, Hamilton B, O'Hagan M, Panther G, Perkins R, Shepherd G, Tse S, Whitley R. Uses and abuses of recovery: implementing recovery-oriented practices in mental health systems. World Psychiatry. 2014;13:12-20.

4. Slade M. Personal recovery and mental illness: a guide for mental health professionals (valuesbased medicine). Cambridge: Cambridge University Press; 2009.

5. Roeg W. Discovering myself, a journey of rediscovery. Ment Health Soc Incl. 2016;20(4): 217-20. https://doi.org/10.1108/MHSI-04-2016-0013.

Open Access This chapter is licensed under the terms of the Creative Commons Attribution 4.0 International License (http://creativecommons.org/licenses/by/4.0/), which permits use, sharing, adaptation, distribution and reproduction in any medium or format, as long as you give appropriate credit to the original author(s) and the source, provide a link to the Creative Commons license and indicate if changes were made.

The images or other third party material in this chapter are included in the chapter's Creative Commons license, unless indicated otherwise in a credit line to the material. If material is not included in the chapter's Creative Commons license and your intended use is not permitted by statutory regulation or exceeds the permitted use, you will need to obtain permission directly from the copyright holder. 